\title{
The Potential of Self-Tempered Martensite and Bainite in Improving the Fatigue Strength of Thermomechanically Processed Steels
}

\author{
Ulrich Krupp ${ }^{1, *}$, Mikhail Solovev ${ }^{1}$, Felix Honecker $^{1}$, Bernhard Adams $^{2}$, and Jan-Christoph Florian ${ }^{3}$ \\ ${ }^{1}$ Institute of Materials Design and Structural Integrity, University of Applied Sciences Osnabrück, 49009 Osnabrück, Germany \\ ${ }^{2}$ Institute of Production Technology, University of Applied Sciences Osnabrück, 49009 Osnabrück, Germany \\ ${ }^{3}$ Georgsmarienhütte GmbH, Neue Hüttenstraße 1, 49124 Goergsmarienhütte, Germany
}

\begin{abstract}
In contrast to a two-stage hardening and tempering process, the definition of optimized cooling routes after hot working of low-alloy $\mathrm{Cr}$ steel allows the adjustments of high-strength microstructures with a sufficient degree of ductility at the same time without any additional heat-treatment. While compressed air cooling after hot forging of micro-alloyed steel grades leads to the formation of lower bainite with finedispersed cementite platelets, quenching by water spray down to the martensite start temperature results in the formation of martensite, that is self-tempered during the subsequent slow-cooling in air. The precipitation of nano-sized cementite precipitates result in superior mechanical properties with respect to impact and tensile testing. Cyclic deformation and crack propagation tests being carried out using resonance testing $(100 \mathrm{~Hz})$ and ultrasonic fatigue testing $(20 \mathrm{kHz})$ systems revealed a pronounced increase in fatigue strength by about $150 \mathrm{MPa}$ of the self-tempered martensite condition as compared to the bainitic modification. For the latter one, a steady decrease of the fatigue strength is observed rather than the existence of a real fatigue limit.
\end{abstract}

\section{Introduction}

Tempered martensitic steels are used in virtually all kind of engineering applications, which imply cyclic deformation at high load levels, e.g., power train in transportation, gear boxes or crack shafts in power generation. The excellent combination of strength and ductility can be attributed to (i) an optimum in size and distribution of carbides, (ii) a small prior austenite grain size and (iii) a sufficient ductility of the martensitic bulk material. These parameters are determined by the way of heat treatment. Typically, the steels are quenched after austenitization followed by a one- or two-stage tempering treatment. More recently, bainitic microstructures have been classified to exhibit a very similar microstructure than tempered martensitic steels (cf. [1]). During rapid quenching, the austenite remains supersaturated in carbon, eventually resulting in small $\varepsilon-$ carbide platelets within the ferritic matrix, when quenching is passed to isothermal phase transformation (cf. Figs. 1 and 4).

Since the establishment of bainitic microstructures is much more cost-efficient than the processing of quenched and tempered steel, research has been focussed to optimize the fatigue properties of bainitic steels (e.g. [2]). With respect to the behaviour in the very-high-cycle fatigue regime (VHCF), the failure mechanisms are not fully understood yet. Even the question about the existence or non-existence of a real fatigue limit cannot be answered today. A characteristic feature of VHCF failures of high strength steels is the occurrence of crack initiation at internal microstructural defects, such as nonmetallic inclusions. The defects are surrounded by a socalled fine-granular or optically dark area (FGA or ODA). The origin of this area is attributed to the accumulation of cyclic plasticity leading to local grain refining (polygonization, [3]) and/or hydrogen concentration [4]. Since the threshold stress intensity range for crack initiation decreases in a refined grain microstructure, the steel may fail at a very low stress amplitude, which is far below the macroscopic threshold for technical fatigue cracks (cf. $[5,6])$.

According to Murakami [7], the fatigue limit of highstrength steels can be correlated with the material's strength (Vickers hardness HV) and the size of the nonmetallic inclusions (projected area), only, according to

$$
\sigma_{F L}=\frac{C(H V+120)}{(\sqrt{\text { area }})^{1 / 6}}\left(\frac{1-R}{2}\right)^{\alpha},
$$

with $R$ being the stress ratio, and $C$ and $\alpha$ being material constants. From the correlation of different steel heat treatments with the respective fatigue properties it is

Corresponding author: $\underline{\text { u.krupp} @ \text { hs-osnabrueck.de }}$ 
known that beside the material's strength and inclusion size, the bulk ductility, the prior austenite grain size as well as the size and distribution of carbides are significant in determining the VHCF behavior of heattreated steel. Hence, it is the aim of the present study to optimize the microstructure of a micro-alloyed forging steel $16 \mathrm{CrMnV} 77$ (German designation) in such a way that it can be used immediately after the forging process without an additional quenching and tempering treatment.

\section{Experimental}

The material studied in the present work is a microalloyed bainitic steel $16 \mathrm{CrMnV} 77$ (German designation), applied for forging applications in automotive industry, e.g., cam shafts. Its chemical composition is given in Table 1 .

Table 1. Chemical composition of the micro-alloyed $16 \mathrm{CrMnV} 77$ grade steel (in wt.\%).

\begin{tabular}{ccccc}
\hline $\mathrm{Fe}$ & $\mathrm{C}$ & $\mathrm{Mn}$ & $\mathrm{Cr}$ & $\mathrm{Mn}$ \\
\hline Bal. & 0.16 & 1.7 & 1.7 & 0.7 \\
\hline & & & & \\
\hline $\mathrm{P}$ & $\mathrm{S}$ & $\mathrm{Ni}$ & $\mathrm{V}+\mathrm{Nb}+\mathrm{Al}+\mathrm{N}$ \\
\hline 0.013 & 0.017 & 0.16 & & 0.17 \\
\hline
\end{tabular}

The steel was delivered as round bars of $50 \mathrm{~mm}$ diameter. Sections of these bars were heated up to $1250^{\circ} \mathrm{C}$ and $950^{\circ} \mathrm{C}$, respectively, by means of an $70 \mathrm{~kW}$ induction coil and hot-forged using a $10000 \mathrm{~N}$ screw press (Weingarten). Immediately after deformation, the bars were quenched according to defined cooling conditions: (i) $1250^{\circ} \mathrm{C}=>$ compressed air to $260^{\circ} \mathrm{C}=>$ keeping isothermally in furnace at $260^{\circ} \mathrm{C}=>$ air-cooling to $\mathrm{RT}$ (cooling rate $t_{8 / 5}=103 \mathrm{~s}$ ), and (ii) water quenching to martensite start temperature $\left(M_{\mathrm{s}}\right)=>$ air-cooling to RT (cooling rate $t_{8 / 5}=56 \mathrm{~s}$ ). The two different cooling conditions are represented in the schematic timetemperature-transformation (TTT) diagram in Fig. 1, where (i) aims to isothermal bainite formation, and (ii) to martensite formation followed by self-tempering during decelerated cooling below $M_{\mathrm{s}}$.

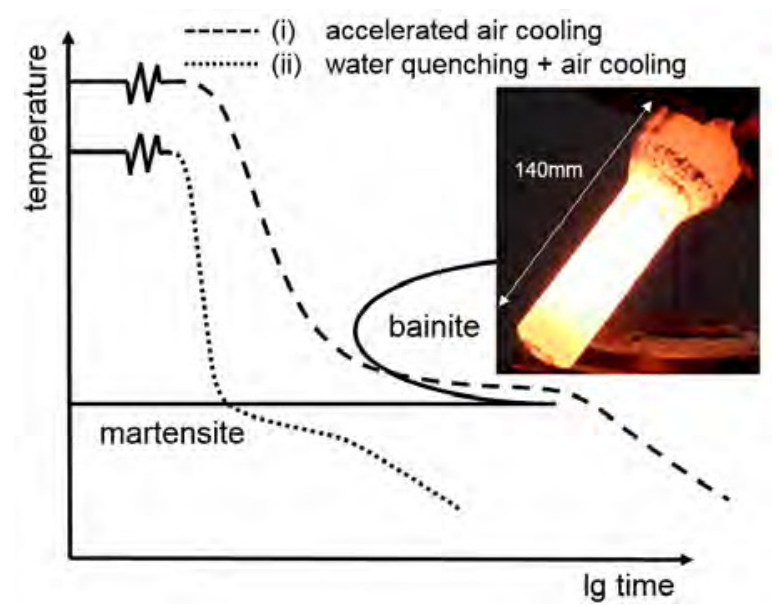

Fig. 1. Thermomechanical processing by means of two different cooling routes in a schematic TTT diagram for the steel 16CrMnV 77 applied to hot-forged bars (photograph). From the thermomechanically processed bars (true deformation strain $\varphi \cong 1$ ), cylindrical specimens for ultrasonic fatigue testing at $19000 \mathrm{~Hz}$ (UFTE system type BOKU Vienna) and for resonance fatigue testing at $95 \mathrm{~Hz}$ (Rumul Testronic 100kN, Fig. 2) were machined. The latter ones were given a shallow notch to allow insitu observation of surface damage by means of digital light microscopy (Hirox, Fig. 2). All tests were carried out under stress control at fully-reversed cycling $(R=-1)$ and terminated when the resonance frequency dropped by $2 \%$, which was attributed to macroscopic fatigue damage (end of life).

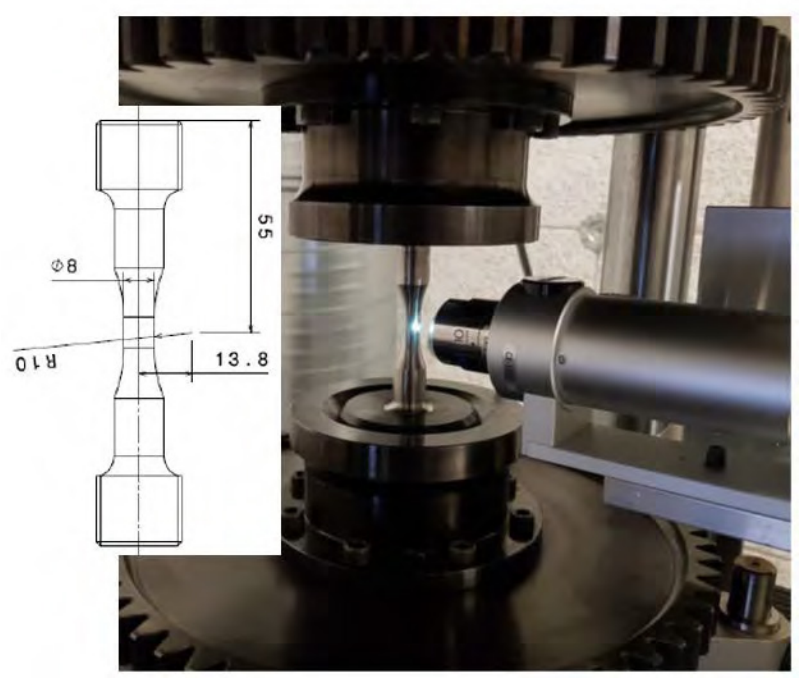

Fig. 2. Resonance fatigue testing (Rumul Testronic) with digital microscope for damage tracking using a shallownotched specimen geometry.

After cycling, the fracture surfaces of the specimens were analyzed by scanning electron microscopy (SEM) in combination with energy-dispersive X-ray spectroscopy (EDS). In the case of internal fatigue crack initiation, the characteristic features, e.g., fine granular areas (FGA), were cut by focused ion beam milling (FIB SEM Zeiss Auriga FEG) to obtain cross-section information about local microstructure changes.

\section{Results and Discussion}

\subsection{Steel Microstructure}

After thermomechanical processing, the forged bars were cut and investigated with respect to (i) grain size, (ii) martensite/bainite lancets, and (iii) size and distribution of cementite precipitates. Fig. 3 shows the light micrographs of the bainitic microstructure (accelerated air cooling, Fig. 3a) and the martensitic microstructure (water-quenching + air cooling, Fig. 3b). Since the bainitic samples were forged at $1250^{\circ} \mathrm{C}$, the prior austenite grain size is much larger $(53 \mu \mathrm{m}$, Fig. $3 \mathrm{a})$ 
than in the case of the martensitic microstructure $(8 \mu \mathrm{m}$, Fig. 3b).

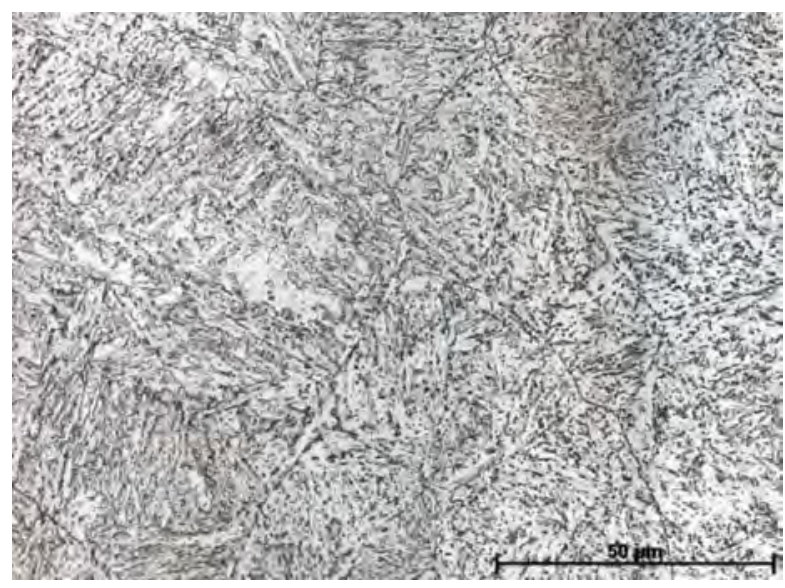

a

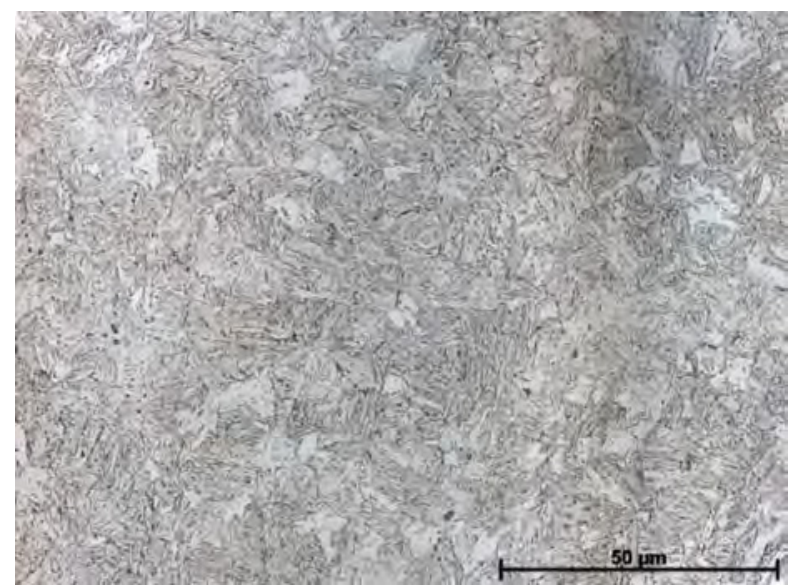

b

Fig. 3. Light micrographs of thermomechanically processed steel 16 CrMnV 7 7: (a) bainitic microstructure after accelerated air cooling, and (b) martensitic microstructure after water quenching and air cooling.

High-resolution SEM revealed a homogeneous distribution of small cementite precipitates. In the case of the bainitic microstructure, the ferrite lancets are separated by thin cementite films, while plate-shaped cementite precipitates of $100-200 \mathrm{~nm}$ length are formed $60^{\circ}$ tilted towards the lancet axes. The corresponding hardness was measured as $372 \mathrm{HV} 30$ and the yield strength as YS=870MPa. In the case of the martensite microstructure, $1 \mu \mathrm{m}$ sized cementite plates are formed along the martensite block boundaries, while tiny $(<100 \mathrm{~nm})$ homogeneously distributed cementite precipitates were identified within the martensite blocks. Obviously, the transition from rapid quenching in water to slow-cooling in air immediately below the martensite start temperature $M_{\mathrm{s}}$ gave rise to self-tempering of the martensite. The hardness and the yield strength of the self-tempered martensite is substantially higher; 461HV30 and YS=1000MPam, respectively. Surprisingly, the ductility of the self-tempered material, measured as Charpy impact work, $A_{\mathrm{v}}=104 \mathrm{~J}$, is much higher than in the case of the bainitic material, $A \mathrm{v}=17 \mathrm{~J}$.

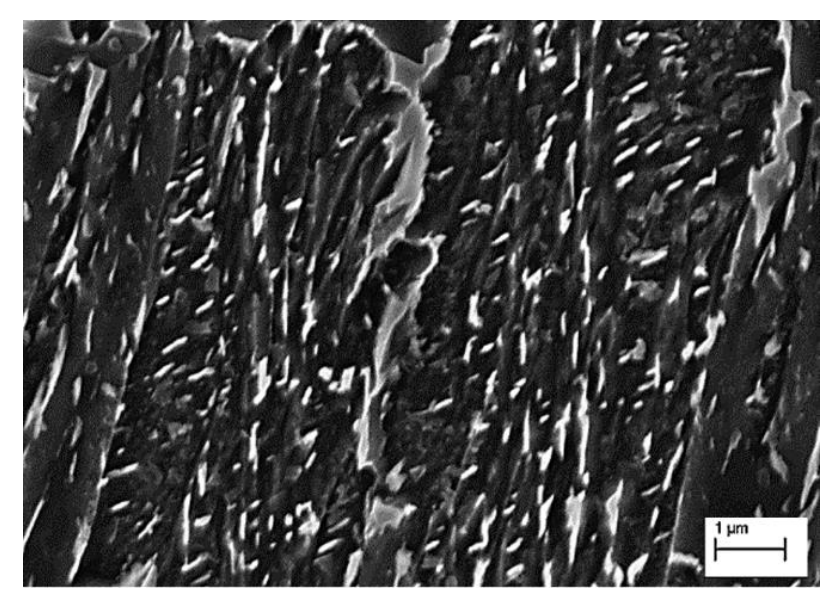

a

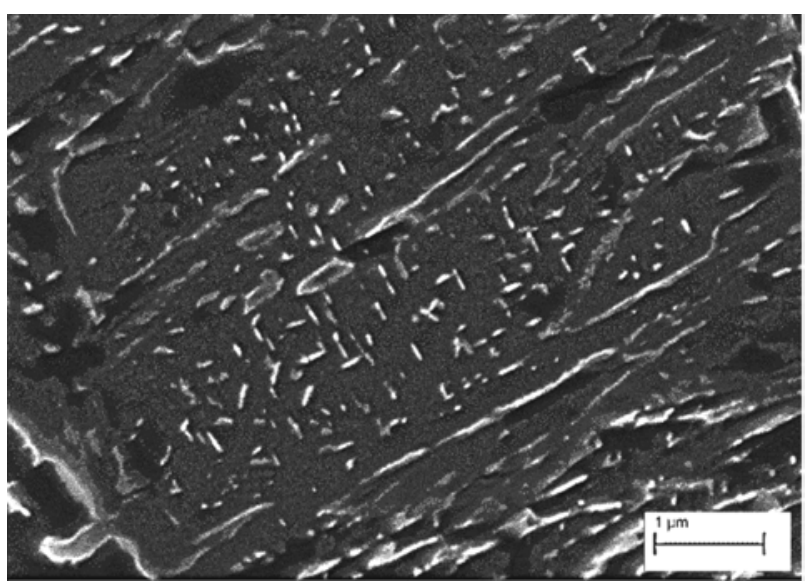

b

Fig. 4. SEM micrographs of thermomechanically processed steel $16 \mathrm{CrMnV} 7$ 7: (a) large cementite precipitates along the bainite lancets and small cementite precipitates tilted by $60^{\circ}$ towards the lancet axes, (b) martensitic microstructure showing nano-sized cementite precipitates as a result of self-tempering.

\subsection{Fatigue Behavior}

Fatigue testing of the thermomechanically processed specimens (according to section 3.1) supported the results of the monotonic tensile tests, i.e., the fatigue strength of the self-tempered martensitic material is substantially higher than that of the bainitic material. This is shown in the $\mathrm{S} / \mathrm{N}$ Wöhler diagrams in Fig. 5 summarizing the results of the fatigue tests. For the bainitic material (Fig. 5a), no failure up to 1 billion cycles was observed at a stress amplitude of $\sigma_{a}=375 \mathrm{MPa}$ (hence, this value can be understood as technical fatigue limit). In the case of the self-tempered martensite (Fig. $5 \mathrm{~b}$ ), the respective fatigue limit was identified at a stress amplitude of $\sigma_{\mathrm{a}}=600 \mathrm{MPa}$. Since the analysis was focused to the fatigue behavior in the HCF and the $\mathrm{VHCF}$ regime, in most cases internal crack initiation was observed; except the four bainitic specimens loaded at stress amplitudes larger than 600MPa (Fig. 5a). 


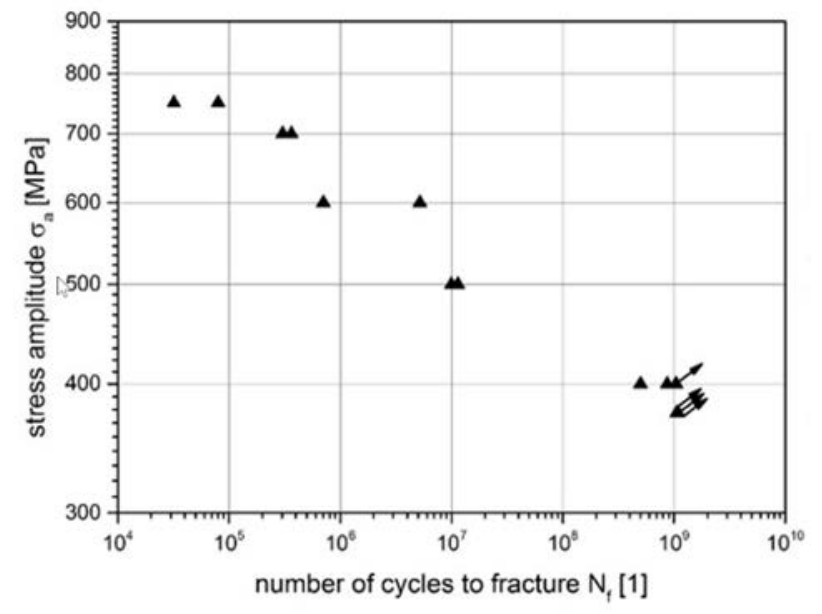

a

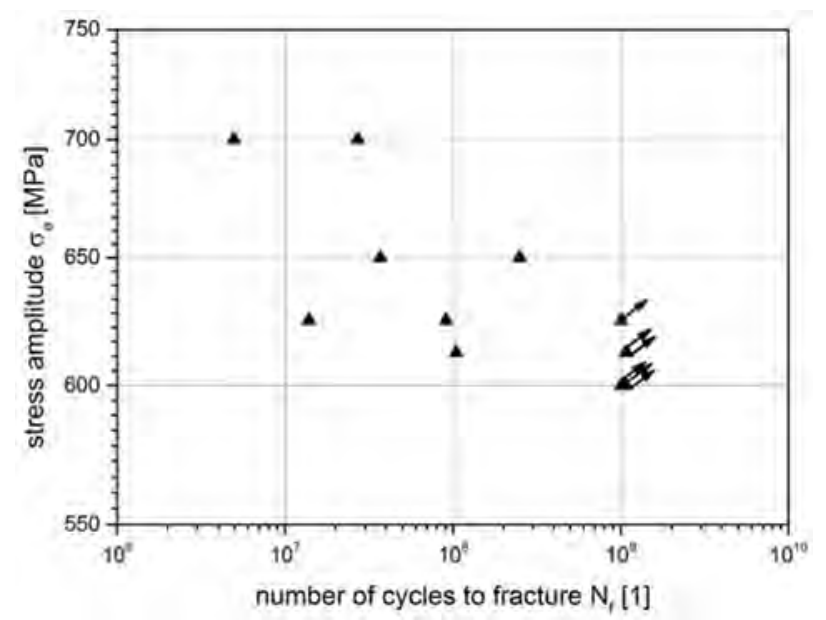

b

Fig. 5. S/N Wöhler diagram of specimens made of thermomechanically processed $16 \mathrm{MnCrV} \mathrm{7} \mathrm{7:} \mathrm{(a)} \mathrm{lower}$ bainite microstructure (after accelerated air cooling), and (b) martensitic microstructure after water quenching and air cooling (UFTE testing was used for VHCF testing at $N>10^{7}$ ).

In the case of the self-tempered martensite, all VHCFloaded specimens showed internal crack initiation (cf. Fig. 6a). By means of fracture surface analyses, nonmetallic inclusions, typically of sizes between $10 \mu \mathrm{m}$ and $30 \mu \mathrm{m}$, were identified as fatigue-crack-initiation sites. As it was reported by various authors before, the inclusions are surrounded by fine granular areas (FGA), the size of which increases with decreasing load amplitude (cf. [6]). Fig. 6b shows a typical example of a mixed Al-Ca-Mg oxide (analyzed by EDS) as VHCFcrack-initiating defect. Accounting to the Murakami equation (eq. 1), the inclusion shown in Fig. 6b $\left(\right.$ area $\left.^{0.5}=17.6 \mu \mathrm{m}^{0.5}\right)$ corresponds to an estimated fatigue limit of $\sigma_{\mathrm{FL}}=562 \mathrm{MPa}$. Actually, the specimen was broken after almost 100 million cycles at a stress amplitude of $\sigma_{\mathrm{a}}=625 \mathrm{MPa}$. Hence, it seems that the Murakami equation provides a rather conservative estimation of the fatigue limit. The majority of the identified crack initiating defects are somewhat larger, i.e. area ${ }^{0.5}$ between $17 \mu \mathrm{m}^{0.5}$ and $56 \mu \mathrm{m}^{0.5}$.

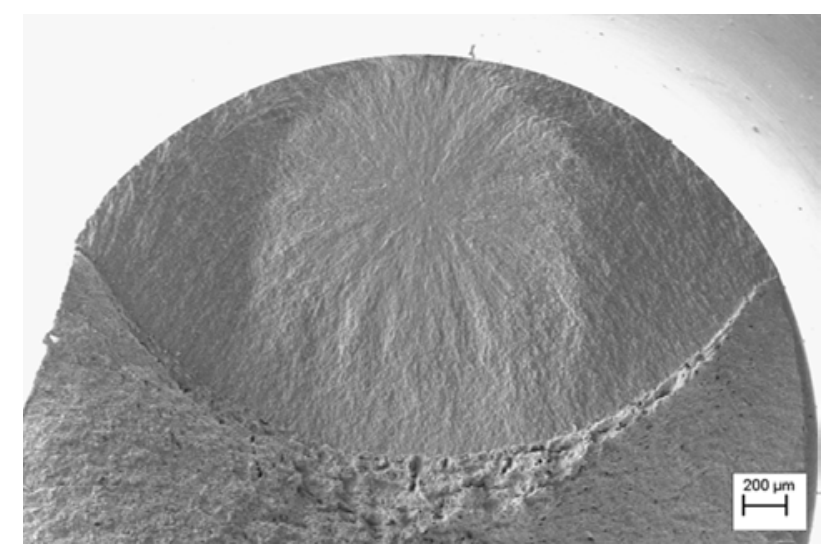

a

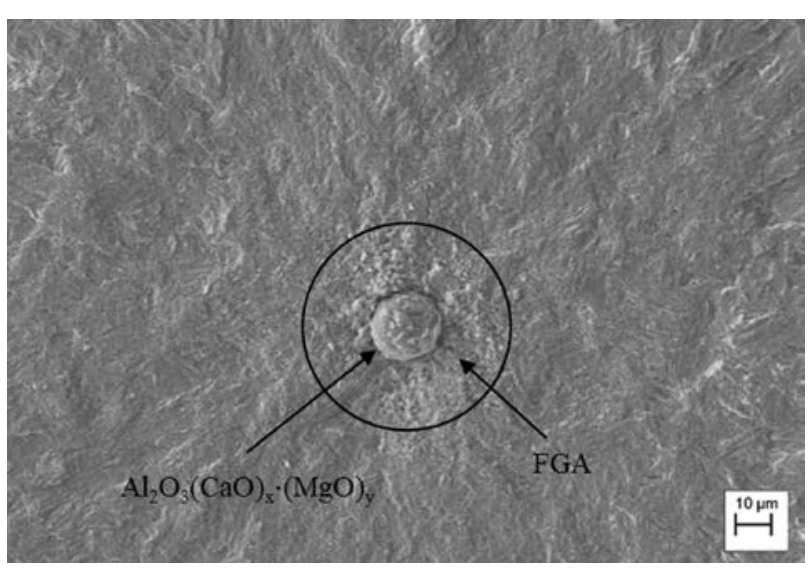

b

Fig. 6. FGA of a self-tempered martensitic specimen failed after 91 million cycles at a stress amplitude of $\sigma_{\mathrm{a}}=625 \mathrm{MPa}$ (cf. Fig. 5b): (a) fracture surface showing FGA at non-metallic inclusion and (b) corresponding FIB section through the FGA.

Within any of the fracture surfaces of the VHCF-loaded bainitic specimens, internal crack initiation and the formation of a FGA was observed as well. However, in no case a non-metallic inclusion was identified as crackinitiating defect (cf. Fig. 7a). This surprising result - the bainitic specimens were produced from the same steel batch than the martensitic ones - is attributed to both (i) the larger prior austenite grain size, probably leading to local stress concentrations that exceed the stress concentrations at the non-metallic inclusions, and (ii) the lower matrix strength, giving rise to a more pronounced cyclic plasticity around the crack-initiating defect. The nature of the non-inclusion FGA itself was proven as to be the same as in the case of the well-known inclusion FGA. FIB milling of the FGA shown in Fig. 7a revealed an approx. $2 \mu \mathrm{m}$ thick nano-grained layer (cf. Fig. $7 \mathrm{~b}$ ). It is worth mentioning that by serial FIB milling several micro debondings were identified, as it is shown in Fig. 7b. The observation of micro decohesion between carbides and matrix along prior austenite grain boundaries as origin of FGA formation was reported by Shiozawa et al. in [8]. Hence, it can be concluded that 
the observed micro-debonding effects are a consequence of microcracking, and are eventually the origin of the formation of a rough FGA layer. Therefore, micro debondings seem to play an important role during VHCF fatigue crack initiation and early growth process. Further analysis of their nature is subject of ongoing work.

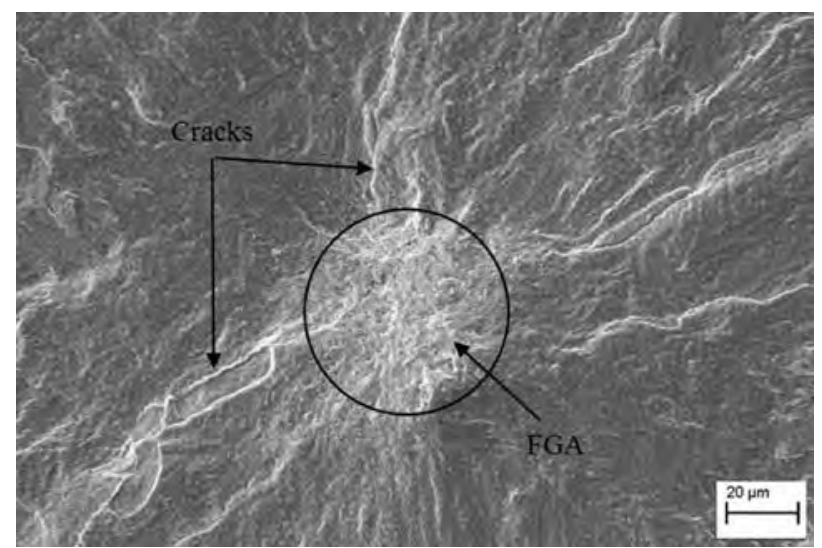

a

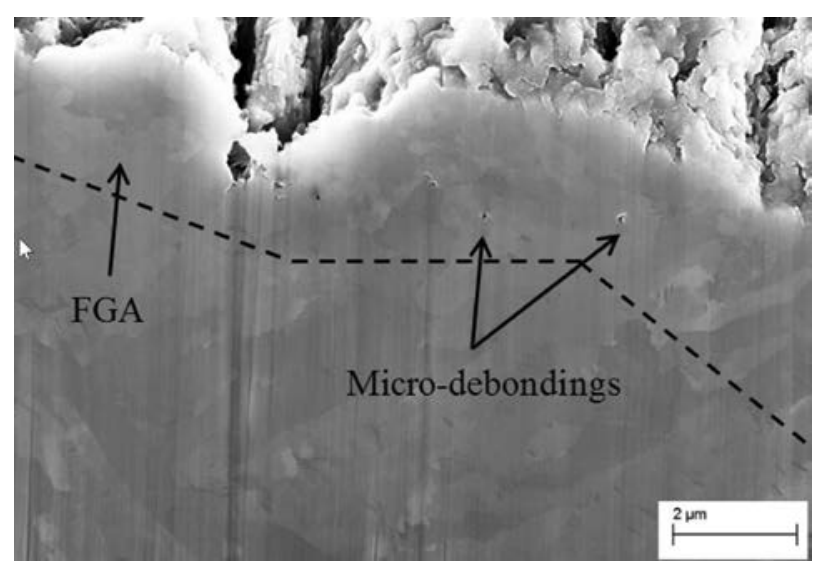

b

Fig. 7. FGA of a bainitic specimen failed after 870 million cycles at a stress amplitude of $\sigma_{\mathrm{a}}=400 \mathrm{MPa}$ (cf. Fig. 5a):

(a) fracture surface showing FGA without any non-metallic inclusion and (b) corresponding FIB section through the FGA.

\section{Conclusions}

Thermomechanical processing of martensitic bainitic steel, i.e., hot forging followed by a defined cooling procedure, allows the establishment of tailored microstructures exhibiting a superior combination of strength and ductility. In the case of a micro-alloyed $0.16 \mathrm{C}-1.7 \mathrm{Mn}-1.7 \mathrm{Cr}$ forging steel, partial quenching in water followed by slow-cooling in air immediately below the martensite start temperature led to a selftempering effect. The resulting homogeneously distributed nano-cementite platelets give the material not only a high yield strength and impact toughness, but also a high fatigue limit of at least $600 \mathrm{MPa}$. In agreement to earlier work, VHCF failure is observed at numbers of cycles exceeding 100 million, typically initiating at internal defects surrounded by a fine granular area
(FGA). Surprisingly, only in the case of the selftempered martensitic structure the FGA is formed around non-metallic inclusions. In the case of the bainitic microstructure, only non-inclusion-type FGAs were identified; obviously in this case, the prior austenite grain boundaries are the weakest link leading to accumulated VHCF strain localization followed by polygonization and crack propagation into the FGA.

\section{Acknowledgement}

The financial support by the Volkswagen foundation (Lower Saxony Germany) in the framework of the research priority program OPTIHEAT and the supply of steel specimen material by Georgsmarienhütte $\mathrm{GmbH}$ are gratefully acknowledged.

\section{References}

1. H.K.D.H. Bhadeshia, Bainite in Steels (The Institute of Metals, London, 2001)

2. E. Kerscher, K.-H. Lang, Proc. Engng 21731 (2010)

3. T. Sakai, J. of Solid Mech. Mater. Engng, 3425 (2009)

4. Y. Murakami, T. Nomoto, T. Ueda, Fatigue Fract. Engng. Mater. Struct. 23893 (2000)

5. P. Grad, B. Reuscher, A. Brodyanski, M. Kopnarski, E. Kerscher, Scripta Mater. 67838 (2012)

6. U. Krupp, A. Giertler, K. Koschella, Fatigue Fract. Engng. Mater. Struct. 40 (2017) 1731

7. Y. Murakami, Metal Fatigue: Effects of Small Defects and Nonmetallic Inclusions (Elsevier, Oxford 2002)

8. K. Shiozawa, Y. Morii, S. Nishino L. Lu, Intern. J. Fatigue 281521 (2006) 